Article

\title{
Damping Behavior of Layered Aluminium and Aluminide Coatings on AISI 316 Austenitic Steel
}

\author{
Ennio Bonetti ${ }^{1}$, Enrico Gianfranco Campari ${ }^{1, *}$, Angelo Casagrande ${ }^{2}$, Giuseppe Catania ${ }^{2}$ \\ and Andrea Garzoni ${ }^{2}$ \\ 1 Dipartimento di Fisica e Astronomia, Bologna University, viale Berti Pichat 6/2, I-40127 Bologna, Italy; \\ ennio.bonetti@unibo.it \\ 2 Dipartimento di Ingegneria Industriale, Bologna University, viale Risorgimento, 4 I-40136 Bologna, Italy; \\ angelo.casagrande@unibo.it (A.C.); giuseppe.catania@unibo.it (G.C.); andrea.garzoni2@unibo.it (A.G.) \\ * Correspondence: enrico.campari@unibo.it
}

Received: 27 July 2020; Accepted: 14 September 2020; Published: 17 September 2020

check for updates

\begin{abstract}
Several coating configurations on AISI 316 steel were obtained by a hot dipping process followed by isothermal interdiffusion. Six different kind of multilayered specimens were produced and characterized. These coatings, typically employed as bond coat in thermal barrier coating (TBC), can also be effective as vibration reduction elements at intermediate and high temperatures. This preliminary work was focused on the microstructural design and processing effects of the coatings. The damping of the produced specimens was measured up to $450{ }^{\circ} \mathrm{C}$ and compared with that of the steel substrate. The most performing coatings contain an Al-Si layer and exhibit a steep damping increase above $200^{\circ} \mathrm{C}$, reasonably due to dislocation movements by plastic straining of soft alloy layer and to the interface sliding between layers with different elastic moduli.
\end{abstract}

Keywords: aluminide; damping; coating; multilayer

\section{Introduction}

Several different types of coatings are used to protect a variety of structural engineering materials from corrosion, wear and erosion and to provide lubrication and thermal insulation. Examples are, in many industrial plants, pumps which drive overheated steam through pipelines. In aircrafts and the automotive industry, there are turbine compressors which inject air into the engine at temperatures which range from $-50{ }^{\circ} \mathrm{C}$ to $500{ }^{\circ} \mathrm{C}$. In the power train of cars and buses, there are ventilation and aeration channels through which hot chemicals flow. All these components work at relatively high temperatures in oxidative and corrosive environments and may need coatings to protect them.

Of all coatings, thermal barrier coatings (TBCs) have the most complex structure and can even operate in the most demanding high-temperature environments. TBCs, which comprise metal, intermetallic, ceramic and multilayers, insulate turbine and combustor engine components from the hot gas stream and improve the durability and the time-life in exercise [1-5].

Materials that are used in structural applications are prone to mechanical vibration, which, when not attenuated, will lead to fatigue of components and shortening of life cycle. Therefore, it is necessary to examine the thermal stability and mechanical properties of coatings under dynamic conditions; the greatest attention is directed towards the bond coat properties, which condition the integrity of the coating. In particular, the study of mechanical energy dissipation is important whenever a thorough understanding of the mechanisms responsible for material damping is required.

A component or a structure can attain high damping by intrinsic or extrinsic methods. Intrinsic methods make use of the inherent ability of some materials to absorb the energy of 
mechanical vibrations through deformations, providing energy dissipation in the form of heat [6]. Commonly used materials for this purpose are polymers due to their viscoelastic character [7-9]. However, viscoelasticity is not the only intrinsic damping mechanism. Defects such as dislocations, phase boundaries, grain boundaries and various interfaces also contribute. Defects may move and surfaces may slip with respect to one another during vibration, thereby dissipating energy. As a consequence, the microstructure greatly affects the damping of materials [10]. Finally, there may be a substantial dependence on temperature for all these effects. An extrinsic method can be considered "system damping" which is damping due to the interactions between all the system components, that is the overall response of the structure. A good example of extrinsic damping is provided by materials in constrained layers, as in the case of multilayer coatings. Of special interest is the use of coatings in the form of diffusion layers of metal alloys, intermetallics and ceramics applied on metallic substrates. The main contribution to damping in these systems is provided by dislocation movements by plastic straining of the soft alloy layer and the interface sliding between layers with different elastic moduli.

Unfortunately, materials which combine high damping and high stiffness are not common. A route to develop a structure or a component which exhibits high stiffness and high damping consists of creating a structure in which a damping coating and high stiffness substrate are coupled [11]. In fact, the use of coatings, as a whole, can provide a simpler, less expensive and reliable solution with regard to an increased vibration damping of mechanical components.

Depending on material choice and treatment, chemical, physical and/or mechanical properties can be emphasized. TBCs of ceramic nature may increase thermal, chemical and mechanical resistance. Among them, aluminide bond coats are particularly interesting. Light, inexpensive, achievable in several layered configurations, their excellent chemical-physical properties must be coupled to a high adhesion resistance to substrate and between layers. Aluminization of stainless steel such as AISI 316, followed by an interdiffusion process, offers the possibility of building several multilayer configurations to assess the influence of the layers' thickness, viscoelasticity, interface and elastic moduli [8]. In this work we produced six different multilayer coatings. In particular, it was decided to evaluate if layers of Aluminum, aluminides and oxides can increase damping because of a relevant extrinsic contribution.

The aluminide coating process used for all specimens described in this work consists of a high temperature diffusion process starting from Aluminium deposition by hot-dip process [12], followed by a thermal diffusion treatment which produces an intermetallic bond layer (Fe-Al aluminide) and a successive oxidation process to create a surface ceramic bond coat (Alumina).

An AISI 316 austenitic steel substrate was used for all coatings. The different layers obtained by inter-diffusion between the substrate and the Al-rich surface, make it possible to achieve a continuous elastic modulus change of the final component. It is therefore possible to develop coating configurations with high damping, oxidation/corrosion resistance and a good chemical inertia. These layers, in adhesion between them and having different elastic moduli, can considerably suppress vibration and noise across a wide frequency and temperature range [13,14]. The $\mathrm{Al}-\mathrm{Si}$ alloy, $\mathrm{Fe}_{2} \mathrm{Al}_{5}$, $\mathrm{FeAl}, \mathrm{NiAl}$ and Alumina are the phases produced in the coatings studied in this work.

It goes without saying that the chemical-physical and mechanical properties of the adhesion interface clearly condition the damping of the system [15]. A strong adhesion of the interfaces, by inter-diffusion mechanisms, with mechanical and chemical continuity between the coating and the metal underneath, has a great influence on damping. However, very little is known about the optimum design of layered coatings and on the damping properties of layered Fe-Aluminides at temperatures in the range $30^{\circ} \mathrm{C}-450{ }^{\circ} \mathrm{C}$. Owing to this fact, this paper is mainly concerned with the measure as a function of temperature of the dynamic elastic modulus and damping properties of inter-diffused layered Aluminum and aluminide coatings on a metallic substrate, compared with the uncoated component. 


\section{Materials and Methods}

The substrate material to be subsequently aluminized is commercial AISI 316 heat-resistant steel. Its composition is listed in Table 1.

Table 1. Nominal chemical composition of AISI 316 steel.

\begin{tabular}{ccccccccccccccc}
\hline wt.\% & Fe & Cr & V & Ni & Mo & Mn & Si & $\mathbf{P}$ & Nb & Al & $\mathbf{C}$ & $\mathbf{N}$ & S & O \\
\hline AISI 316 & Bal & 18.29 & 0.10 & 8.75 & 1.94 & 0.56 & 0.47 & 0.021 & 0.08 & $\leq 0.01$ & 0.35 & 0.079 & 0.0033 & 0.0049 \\
\hline
\end{tabular}

Before starting with the coating procedure, the specimens (dimensions: $50 \times 5 \times 0.5 \mathrm{~mm}^{3}$ ) were ground up to 800-grit SiC paper and then degreased in ethanol in an ultrasonic bath for $10 \mathrm{~min}$.

Layered Aluminum and aluminide coatings were produced by a hot-dipping process on sheets of AISI 316 with an Al-Si hypoeutectic alloy [16] in a glove box with a furnace connected to an inert gas to minimize oxidation. All specimens were kept at $750{ }^{\circ} \mathrm{C}$ for $5 \mathrm{~min}$ in a bath inside an alumina crucible and were subsequently removed and cooled in air. The bath composition of the Al-Si had a 7\% weight Si content. The thickness of the as dipped aluminized coating was about $200 \mu \mathrm{m}$. The coating was formed by Al-Si alloy with an inner intermetallic $\mathrm{Fe}_{2} \mathrm{Al}_{5}$ as bond coat. Both sides of the metal plates have an equal layer sequence.

Six different coatings were produced:

(1) As aluminized by a 5 min hot-dipping (Figure 1a), having an inner intermetallic layer and an outer Al-Si alloy layer, $200 \mu \mathrm{m}$ thick.

(2) As aluminized by a 3 min hot-dipping (Figure 1b), having an inner intermetallic layer and an outer Al-Si alloy layer, $130 \mu \mathrm{m}$ thick.

(3) As aluminized by hot-dipping and successively oxidized in furnace at $900{ }^{\circ} \mathrm{C}$ for $1 \mathrm{~h}$ (Figure $1 \mathrm{c}$ ). The resulting multilayered coating consists of an inner intermetallic Fe-Al layer, an intermediate Al-Si alloy layer and an outer Aluminium oxide layer, having about $10 \mu \mathrm{m}$ thickness.

(4) As aluminized and then layered by a short isothermal interdiffusion process (Figure 1d). The hot-dipped sheets where diffusion annealed at $900{ }^{\circ} \mathrm{C}$ for $3 \mathrm{~h}$ in a box furnace containing a metallic Titanium sheet getter in order to reduce the Oxygen content in the treating atmosphere and to promote the formation of a diffusion coating consisting of an inner FeAl and an outer $\mathrm{Fe}_{2} \mathrm{Al}_{5}$ layer. These sheets were subsequently oxidized in $\mathrm{O}_{2}$-rich atmosphere at $900{ }^{\circ} \mathrm{C}$ for $30 \mathrm{~min}$.

(5) Same thermal treatment as in 4, except that the diffusion annealing at $900{ }^{\circ} \mathrm{C}$ lasted for $4 \mathrm{~h}$ (Figure 1e).

(6) As aluminized and layered by extended isothermal interdiffusion process (Figure 1f). The hot-dipped sheets were diffusion annealed at $850{ }^{\circ} \mathrm{C}$ for $50 \mathrm{~h}$ to complete the $\mathrm{Fe}_{2} \mathrm{Al}_{5}$ transformation in FeAl and to simultaneously form a Ni-aluminide at the substrate/FeAl interface by inward $\mathrm{Al}$ diffusion from the coating and outward Ni diffusion from the substrate. These specimens were subsequently oxidized at $900{ }^{\circ} \mathrm{C}$ for $5 \mathrm{~h}$ in a box furnace. The resulting coating therefore consists of a NiAl layer at the substrate interface, a FeAl layer on top of it and an outer $\mathrm{Al}_{2} \mathrm{O}_{3}$ layer.

Time and temperature were chosen for all coatings in order to create a thin $\alpha-\mathrm{Al}_{2} \mathrm{O}_{3}$ layer (at least $900{ }^{\circ} \mathrm{C}$ is required to this purpose) and to modulate the thickness of the brittle $\mathrm{Fe}_{2} \mathrm{Al}_{5}$ layer. The six different coatings were characterized by optical microscopy (OM) with a Reichert-Jung MeF3A (Reichert, Munich, Germany) and by scanning electron microscopy (SEM) with a Zeiss EVO 50. Observations (Zeiss, Oberkochen, Germany) were carried out on: (a) a cross section of the as Aluminium-coated specimens; (b) the same specimens after the heat-diffusion treatment; (c) AISI 316 stainless steel. Etching was performed with gliceregia reagent $\left(\mathrm{HNO}_{3}+\mathrm{HCl}+\mathrm{Glycerol}\right.$, 1:2:1). The coatings composition, before and after the diffusion annealing, was determined by an EDS spectrometer INCA X-ACT by Oxford Instruments (Oxford Instruments, Abingdom, UK). 
The calculated semi-quantitative compositions, for each phase, were averaged out of five values. The layers stoichiometry composition before and after isothermal annealing treatments were identified, after layer by layer abrasion, by a Philips X-ray diffractometer (Philips, Eindhoven, The Netherlands) with $\mathrm{Cu} \mathrm{K}$ adiation with $0.22 \theta$ step size and $1 \mathrm{~s}$ scan step time. Dynamic elastic modulus and damping were measured in vacuum by means of the mechanical analyzer VRA 1604 (Cantil, Bologna, Italy) $[17,18]$. In the VRA apparatus, specimens are mounted in free-clamped mode and excited in flexural vibrations by means of an alternating electrical potential difference applied between the specimen and an electrode. The damping value $\left(Q^{-1}\right.$, as the damping parameter is commonly referred to) is obtained from the envelope of the decreasing oscillation amplitude of the specimen when excitation is turned off. It is a measure of the ratio between energy dissipation and elastic energy stored in the specimen during each oscillation cycle. Therefore, $Q^{-1}=\Delta E /(2 \pi E)$ [19]. Dynamic elastic modulus is obtained from the specimen shape and resonance frequency. Specimens are kept into resonance while temperature is changing at the selected rate. The resonance frequency of all specimens is in the 200-1000 Hz range; the strain amplitude is about $10^{-5}$. Samples are heated from room temperature up to a maximum temperature of $780 \mathrm{~K}$ at $1.5 \mathrm{~K} / \mathrm{min}$ rate.
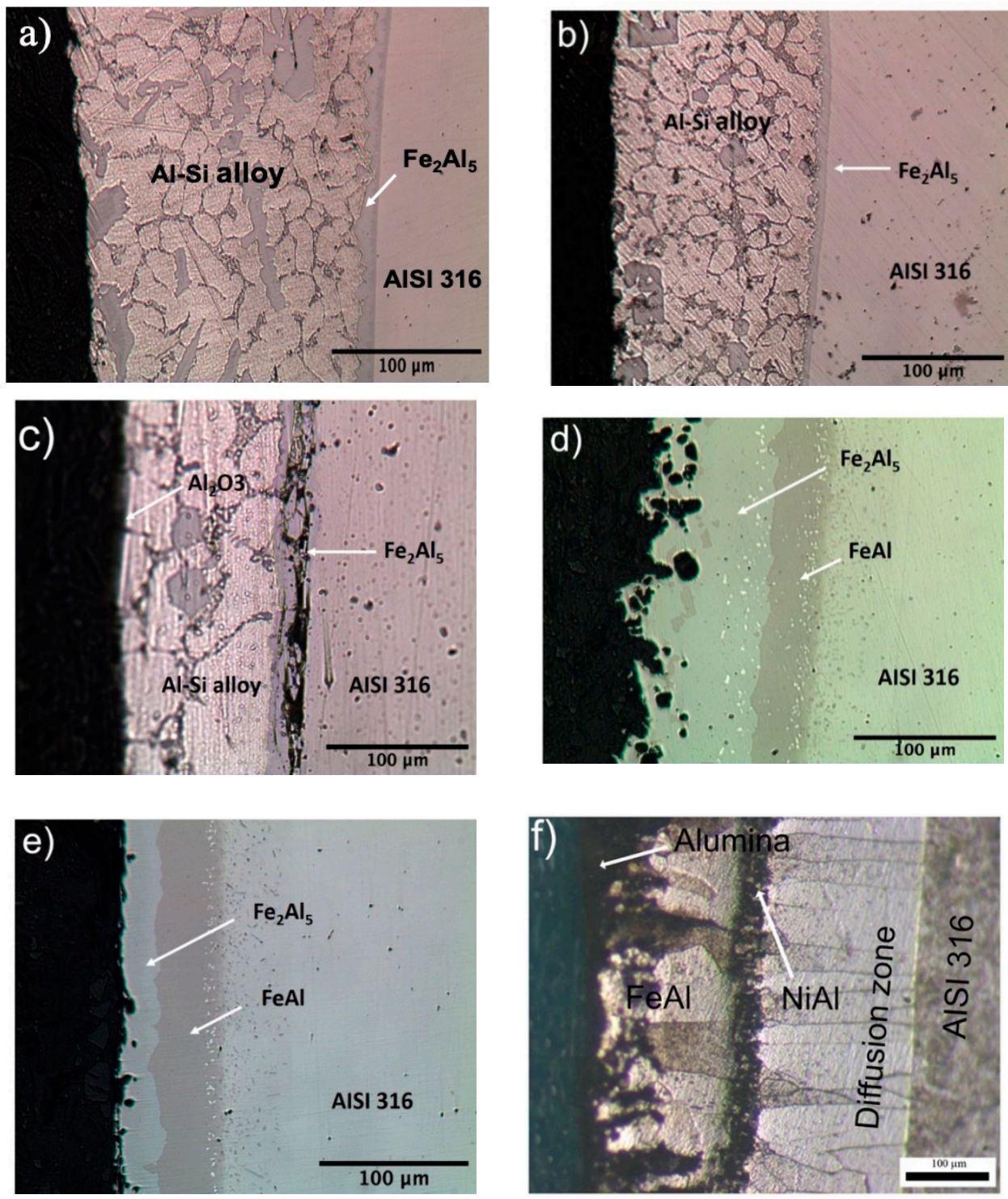

Figure 1. Optical microstructure of cross sections: (a,b) as aluminized; (c) as aluminized plus oxidation at $900{ }^{\circ} \mathrm{C}$ for $1 \mathrm{~h} ;(\mathbf{d}, \mathbf{e})$ as aluminized and annealed at $900{ }^{\circ} \mathrm{C}$ for $3 \mathrm{~h} ;(\mathbf{f})$ as aluminized and annealed at $850{ }^{\circ} \mathrm{C}$ for $50 \mathrm{~h}$. 


\section{Results and Discussion}

\subsection{Microstructural Characterization and Composition Identification}

The transverse sections of hot dip aluminized AISI 316 coatings as observed in optical microscopy, are shown in Figure 1a,b. Two layers are clearly visible: an outer layer made of Al-Si alloy and an inner layer made of the intermetallic $\mathrm{Fe}_{2} \mathrm{Al}_{5}$ [20], as also confirmed by XRD pattern, Figure 2. The layer at the steel interface is produced by inter-diffusion during the hot process, in agreement with the diffusion rate of Iron in Aluminum being faster than that of Aluminum in Iron [21]. The rugged interface between the $\mathrm{Fe}_{2} \mathrm{Al}_{5}$ layer and the Al-Si layer, with tongue-like morphology [22], is due to an interface moving towards the liquid Aluminum, which corresponds to a solid expansion and a predominance of phase growth over dissolution. The size difference of the tongue structure is due to a longer immersion time for the former specimen with respect to that of the latter. Moreover, with longer immersion times the interface tends to flatten, as observed in our specimens. The overall thickness of the aluminized coatings is approximately 130-200 $\mu \mathrm{m}$. The Al-Si alloy layer produced metallographic evidence which comprises a dispersed Al-Si eutectic phase with large precipitates having the shape of needles and platelets with the same composition as the adjacent $\mathrm{Fe}_{2} \mathrm{Al}_{5}(\mathrm{Si}-\mathrm{Cr})$ phase. These precipitates are due to dissolution and spalling of the intermetallic diffusion layer $[20,21]$.

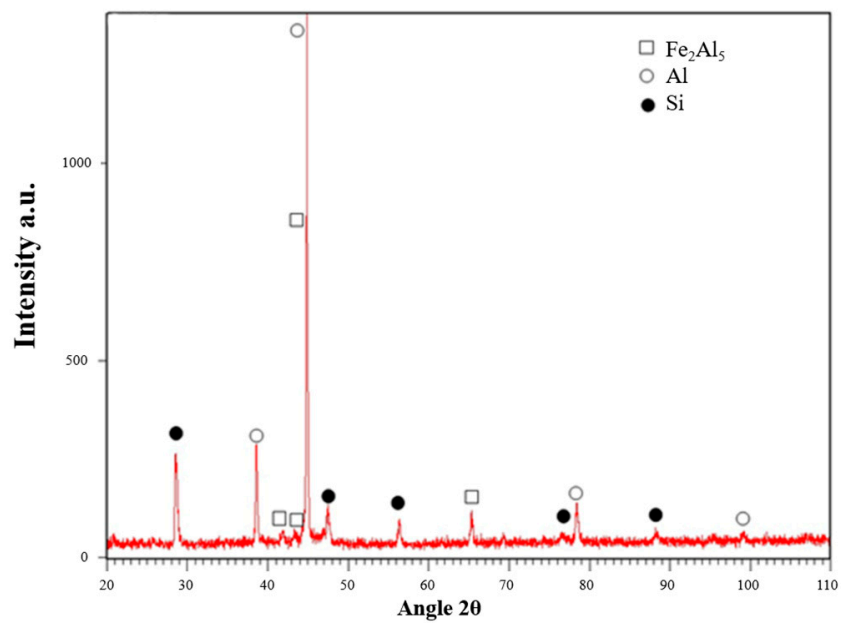

Figure 2. X-ray diffraction of as aluminized coating. Coating as for specimen of Figure 1 a.

In order to optimize the protective coating structure, suitable heat treatments at $900{ }^{\circ} \mathrm{C}$ in the furnace box were carried out after the aluminizing process. The treatments, followed by natural cooling rate, yielded:

- In the case of reduced oxidation, the complete transformation, of the Al-Si alloy layer into an intermetallic $\mathrm{Fe}_{2} \mathrm{Al}_{5}(\mathrm{Si}-\mathrm{Cr})$ layer with successive partial transformation into a softer FeAl phase, as shown in the optical micrograph of Figure 1d,e, in the XRD diffraction pattern of Figure 3 and in the EDS analysis of Table 2. The absence of $\alpha-\mathrm{Al}_{2} \mathrm{O}_{3}$ in the X-ray diffraction of Figure 3 is due to the treatment being done in a poor Oxygen atmosphere. The formation of pores in the specimen of Figure $1 \mathrm{~d}$ is the consequence of the Kirkendall effect, due to the different speeds of diffusion of the elements. 


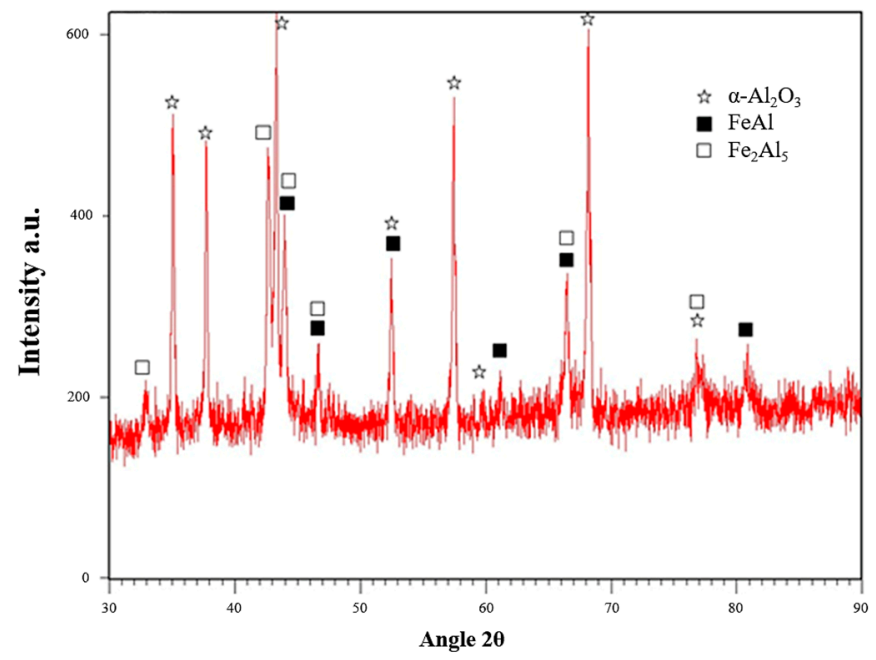

Figure 3. X-ray diffraction of diffusion aluminide coating: $900^{\circ} \mathrm{C}$ for 3 and $4 \mathrm{~h}$. Coating as for specimens of Figure 1d,e.

Table 2. Elemental semi-quantitative EDS analysis of coating layers on AISI 316. The phases are those indicated in the specimens of Figure $1 \mathrm{e}\left({ }^{*}\right)$ and Figure $1 \mathrm{f}(\#)$.

\begin{tabular}{ccccccc}
\hline AISI 316 * & O at.\% & Al at.\% & Fe at.\% & Cr at.\% & Ni at.\% & Si at.\% \\
\hline Outer oxyde layer \# & 64.5 & 30.6 & 1.3 & 2.9 & - & 0.7 \\
Diffusion layer (FeAl) * and \# & - & 47.2 & 40.3 & 4.3 & 6.5 & 1.2 \\
Intermediate Layer (Fe $\mathbf{A l}_{5}$ ) * & - & 56.2 & 30.3 & 6.2 & - & 7.3 \\
$\quad$ Inner layer (NiAl) \# & - & 36.1 & 22.8 & 4.1 & 34.4 & 2.6 \\
$\begin{array}{c}\text { Solid solution by Al diffusion } \\
\text { into substrate \# }\end{array}$ & - & $8.4-12.1$ & 63.6 & 19.1 & 6.6 & - \\
\hline
\end{tabular}

-In the other, formation of an alumina layer on top of the Al-Si alloy layer by oxidation in a $\mathrm{O}_{2}$-rich atmosphere, as shown in the optical micrograph of Figure 1c, in the SEM micrograph of Figure $4 \mathrm{a}$ and in the EDS X-ray map of Figure $4 \mathrm{~b}$. Diffusion at high temperature, needed in order to produce $\alpha$ alumina, increases the thickness of $\mathrm{Fe}_{2} \mathrm{Al}_{5}$, which in turn increases specimen hardness and brittleness.

In the case of the extended isothermal interdiffusion process, a complete transformation of the intermetallic $\mathrm{Fe}_{2} \mathrm{Al}_{5}(\mathrm{Si}-\mathrm{Cr}$ ) into the more ductile $\mathrm{FeAl}$ phase, as detected by XRD diffraction spectra, Figure 5, by optical metallography cross section, Figure 1f, and by chemical EDS analyses, Table 2 . During the treatment at $850{ }^{\circ} \mathrm{C}$ for $50 \mathrm{~h}$, a two steps process occurs: Aluminum diffusion across the coating and its reaction, at the substrate-coating interface, with the alloying elements of the substrate, that is $\mathrm{Fe}, \mathrm{Cr}$ and $\mathrm{Ni}$. The treatment also yields, at the steel interface, an inner NiAl layer, as revealed by the optical micrograph of Figure $1 \mathrm{f}$ and by the EDS chemical analysis reported in Table 2. As a result, the coating is made of an external oxide layer, a thick FeAl intermediate layer and an inner NiAl layer with a few pores near the sample surfaces. According to the binary Al-Ni phase diagram, the Al-Ni rich region at the FeAl interface should be the ordered $\mathrm{B} 2$ phase [23]. This is supported by EDX data, yielding a one to one stoichiometry ratio for $\mathrm{Ni}$ and $\mathrm{Al}$. Noteworthily, Fe has been reported to substitute for both $\mathrm{Al}$ and Ni sites [24].

As far as the adherence of layers to substrates and between them is concerned, the coefficient of thermal expansion (CTE) and particularly its temperature dependence becomes very important. This is because the thermal expansion mismatch between a metallic substrate and its coating generates a strain on cooling that is the primary cause of spallation of protective coatings. The average coefficients of thermal expansion for the aluminides [25] are lower than those of the AISI 316 steel $\left(17 \times 10^{-6} / \mathrm{K}\right)$, and the same is true for the coefficient of thermal expansion of $\mathrm{Al}_{2} \mathrm{O}_{3}$, ranging from $6.7 \times 10^{-6} / \mathrm{K}$ to $8 \times 10^{-6} / \mathrm{K}$ [26] in the studied temperature range. The requirements of an appropriate coating 
system with reference to its CTE substrate are given by the following inequality: CTE substrate $>$ CTE aluminide bond coating $>$ CTE oxide [20]. As a consequence, some problems might occur in coatings with long oxidation time at temperatures as high as $850{ }^{\circ} \mathrm{C}$ since, in these conditions, the $\mathrm{NiAl} / \mathrm{FeAl}$ interface shows a CTE which is lower than both that of FeAl and AISI 316 [21,27]. The $\alpha$-alumina grown on the coating surface has on the other end a better adhesion to the FeAl phase owing to its rugged interface, see Figure $4 \mathrm{a}$. This mechanical adhesion helps to increase the spallation resistance of coatings.
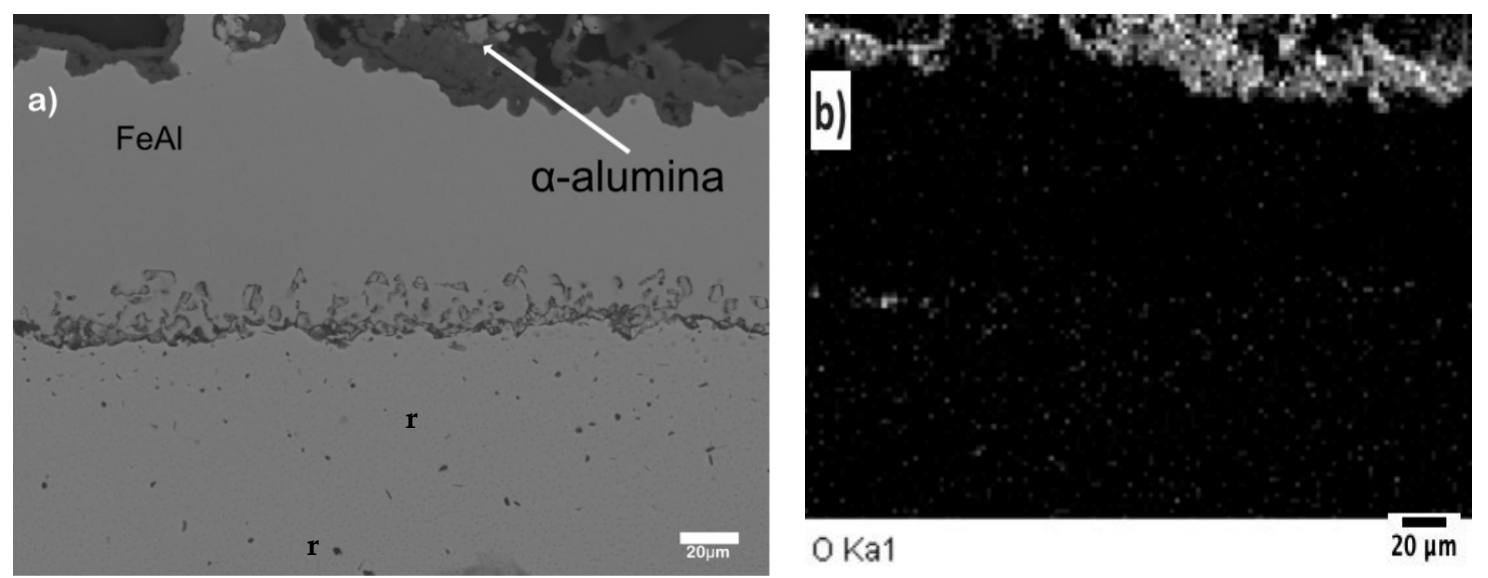

Figure 4. (a) SEM micrograph of cross section of specimen c of Figure 1; (b) EDS X-ray map of the same specimen.

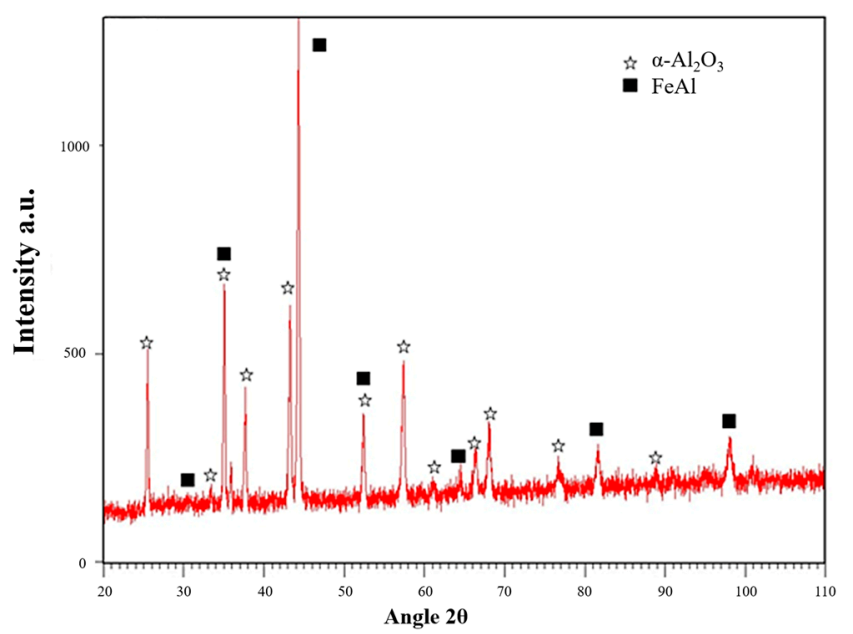

Figure 5. X-ray diffraction of diffusion aluminide coating: $850{ }^{\circ} \mathrm{C}$ for $50 \mathrm{~h}$. Coating as for specimen of Figure 1f.

\subsection{Damping Behavior}

Energy dissipation in industrial components is due to a combination of the following mechanisms: viscous damping, hysteretic damping, friction damping. Models can be built to simulate the overall material behavior. These cooperative models, that try to evaluate the dissipative damping behavior, become very complex when they try to simultaneously simulate multi-layered structures. This complexity stems from the variety of energy dissipation mechanisms in multi-layered structures that, in turn, depend on parameters such as frequency, amplitude and temperature. In this work, tests were carried out in the temperature range $30{ }^{\circ} \mathrm{C}-450{ }^{\circ} \mathrm{C}$ in single cantilever mode with the apparatus described in the experimental procedures. The damping behavior of the multilayered structures is shown in Figures 6 and 7. In this figure and the followings, specimens labeled from A to F have coating corresponding to those labeled from (a) to (f) in Figure 1. 


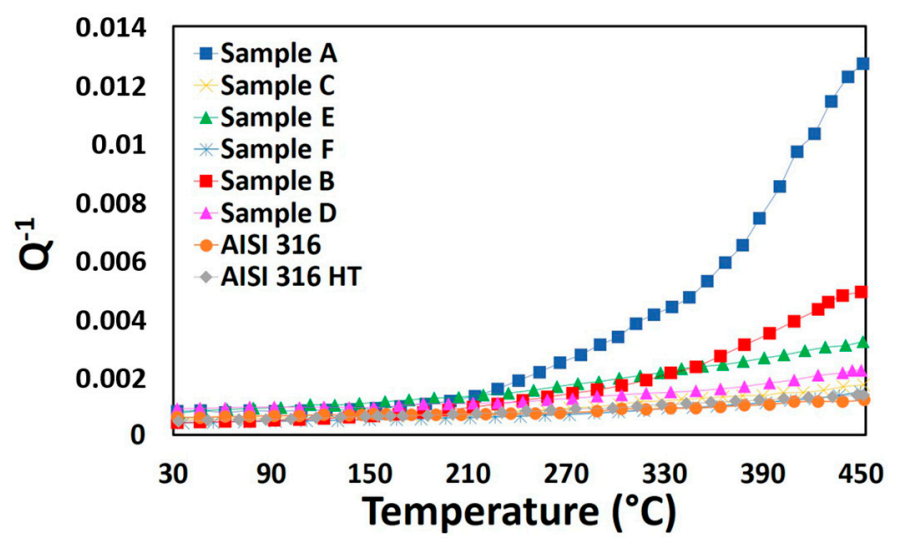

Figure 6. $Q^{-1}$ vs. temperature for hot dipped and thermally annealed specimens in comparison with AISI 316 steel before and after annealing to $900{ }^{\circ} \mathrm{C}$.

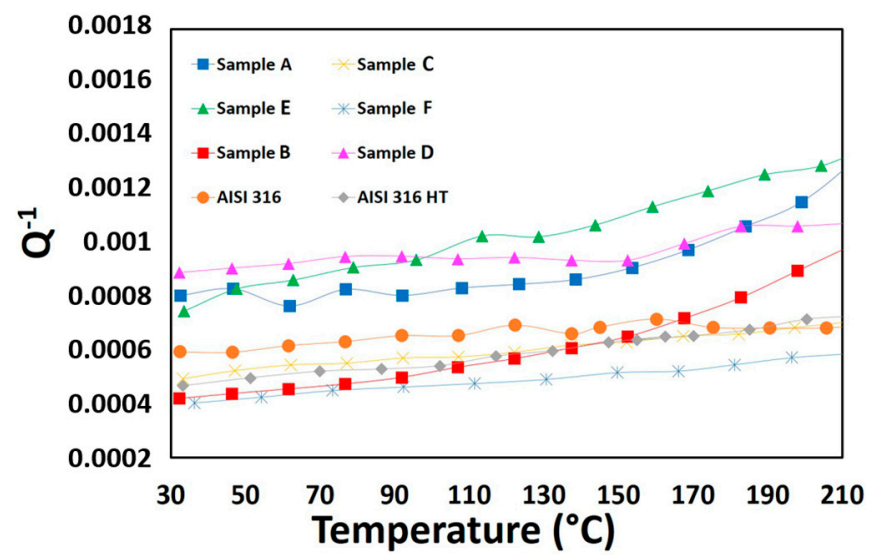

Figure 7. $Q^{-1}$ vs. temperature for hot dipped and thermally annealed specimens in comparison with AISI 316 steel. Enlargement of the previous graph in the temperature range $30^{\circ} \mathrm{C}-210{ }^{\circ} \mathrm{C}$.

Noteworthily, all coatings exhibit, with different degrees, increased damping with respect to that of the uncoated steel, as reported in Figures 6 and 7. This increase is due to coating and becomes considerable for the case of the structure composed by a thin aluminide bond coat and an outer thick Al-Si alloy layer (specimen $\mathrm{A}$ and $\mathrm{B}$ ) discrete and promising for the $\mathrm{FeAl} / \mathrm{Fe}_{2} \mathrm{Al}_{5}$ configuration (specimen $\mathrm{D}$ and $\mathrm{E}$ ). The latter configuration exhibits two layers grown to different thicknesses by interdiffusion process. In one case the $\mathrm{FeAl}$ layer has a thickness of about $50 \mu \mathrm{m}$ while the $\mathrm{Fe}_{2} \mathrm{Al}_{5}$ layer has a thickness of about $20 \mu \mathrm{m}$, specimen E. In the other case, specimen D, the thicknesses of the individual layers are reversed, with $\mathrm{FeAl} 30 \mu \mathrm{m}$ and $\mathrm{Fe}_{2} \mathrm{Al} 100 \mu \mathrm{m}$ thickness, as a result of a different time for the thermal treatment

As shown in Figures 6 and 7, the damping behavior of uncoated AISI 316 and AISI 316 HT, that is before and after annealing to $900{ }^{\circ} \mathrm{C}$ for $3 \mathrm{~h}$, is mostly the same. In the case of the layered specimens, experimental data can be analyzed in terms of a substrate contribution plus a layer contribution. This was accomplished on the specimens of Figure 8. It is possible to compute the layer contribution using the equation [28]:

$$
Q_{f}^{-1}=Q_{c}^{-1}+(1 /(\varphi-1))\left[Q_{c}^{-1}-Q_{s}^{-1}\right]
$$

where the subscripts $f, c$ and $s$ refer to single layer, composite multilayer and AISI 316 substrate, respectively, and $\varphi$ is:

$$
\varphi=\left[\left(f c^{2} \cdot l c^{4}\right) /\left(f s^{2} \cdot l s^{4}\right)\right]\left[1+\left(\rho_{f} t_{f} / \rho_{s} \cdot t_{s}\right)\right]
$$

where $l, t, \rho$, and $f$ refer to the length, thickness, density, and resonance frequency of the specimen. 


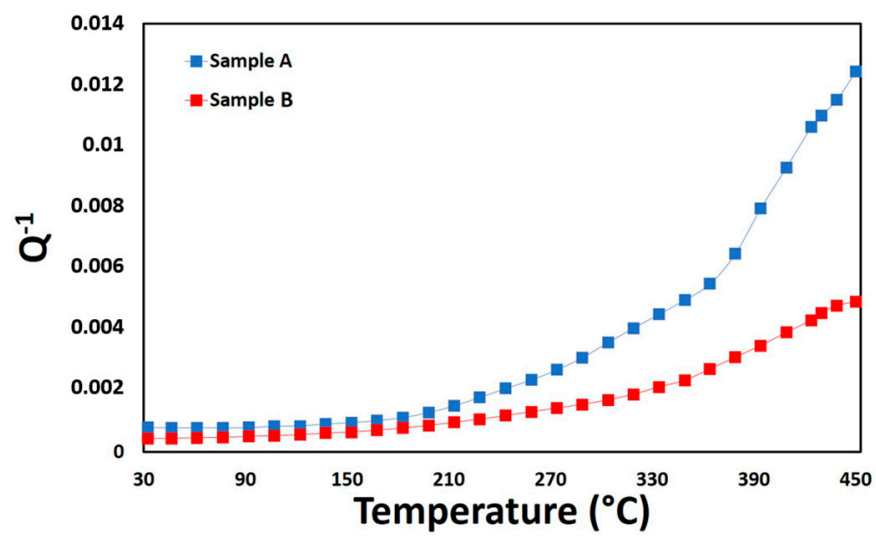

Figure 8. $Q^{-1}$ vs. temperature for as aluminized specimens with different coating thickness.

This analysis allows the damping contribution of the aluminized layers to be better appreciated, as reported in Figures 9 and 10 for specimens A and B.

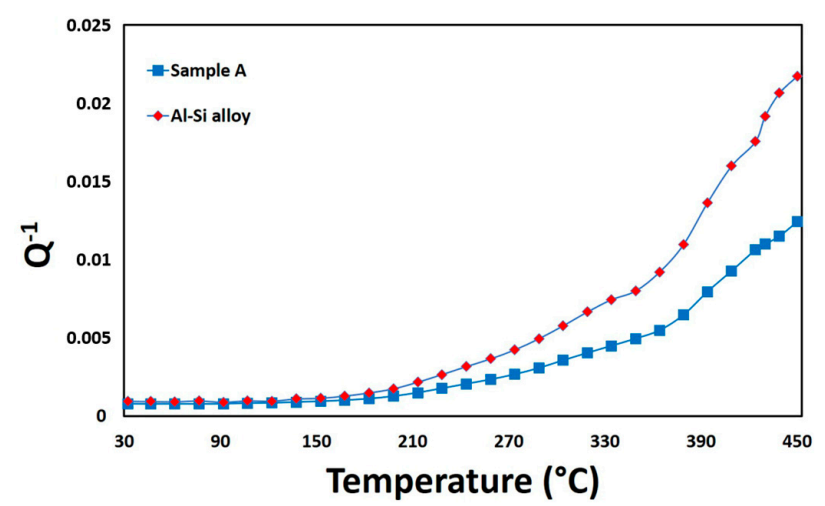

Figure 9. $Q^{-1}$ vs. Temperature curves of sample A after the subtraction of the substrate contribution.

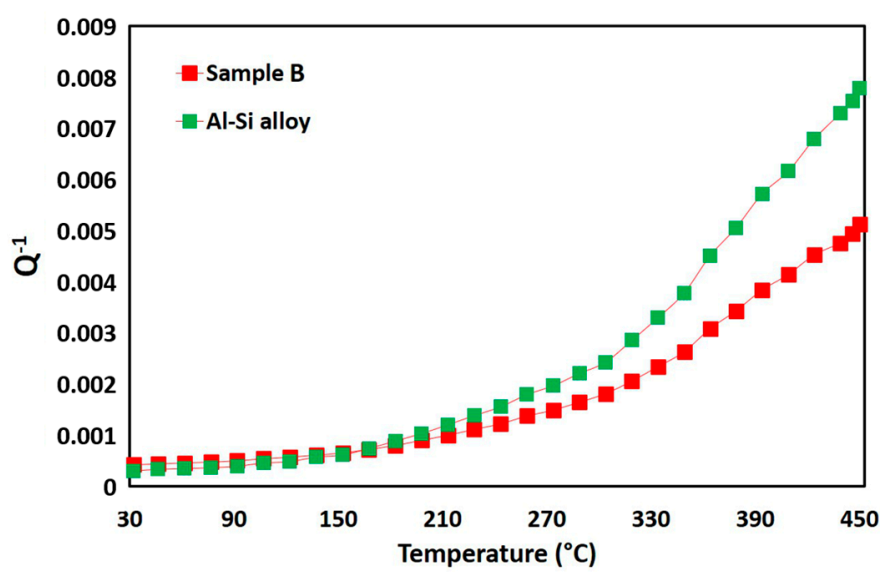

Figure 10. $Q^{-1}$ vs. Temperature curves of sample B after the subtraction of the substrate contribution.

The major contribution to damping for specimens A and B is due to the Al-Si alloy layer. The elastic Young's modulus of low melting metallic alloys, such as the Al-Si alloys used to coat the AISI 316 steel, significantly decreases with a relatively small temperature increase starting from room temperature, together with the yield stress. This coating configuration possesses a high dislocation density at the interfaces, produced during the cooling process, Al-Si solidification and interdiffusion. A high dislocation density is expected because of the lattice misfit at the boundary between the $\mathrm{FaAl}$ and $\mathrm{Fe}_{2} \mathrm{Al}_{5}$ phases. In such a case, an interface with a high dislocation density is expected in order to accommodate the resulting stress. The internal friction fast increase above $150{ }^{\circ} \mathrm{C}$ is due to dislocation 
bowing and comes together with a significant reduction in elastic modulus. In this configuration, energy dissipation is due to the contribution of both viscous damping, internal damping, and interface damping at the substrate/aluminide interlayer. The high local deformation in and near the interface layer can improve damping because of the relevant energy-storing effect. In specimens $\mathrm{E}$ and $\mathrm{F}$, thermal treatments such as keeping the specimen at $900{ }^{\circ} \mathrm{C}$ for short times, 3 and $4 \mathrm{~h}$, do not lead to the complete transformation of the $\mathrm{Fe}_{2} \mathrm{Al}_{5}$ intermetallic phase in the $\mathrm{FeAl}$ phase. The transformation being incomplete, a composition gradient is present which can hinder the bond shear strength and increase the adhesion, because the layer interfaces show a partial crystallographic coherence which opposes the crack formation.

The damping behavior of the coating configuration of specimens E and D, as reported in Figure 11, is less effective in increasing damping in comparison with specimens $\mathrm{A}$ and $\mathrm{B}$. The increase with temperature is not as steep as in specimen A, reasonably, due to the lower dislocation density and viscoelasticity. The main contribution to damping of the coating configuration of specimens $\mathrm{E}$ and $\mathrm{F}$ is provided by the slip resistance of interfaces and by the mismatch of elastic moduli with temperature. As reported by other Authors [29], the Young's modulus of aluminides with high $\mathrm{Al}$ content $\left(\mathrm{Fe}_{2} \mathrm{Al}_{5}\right)$ decreases significantly when temperature is increased. Much less relevant on the contrary is the Young's modulus decrease when the aluminide (FeAl) has a lower $\mathrm{Al}$ content [30].

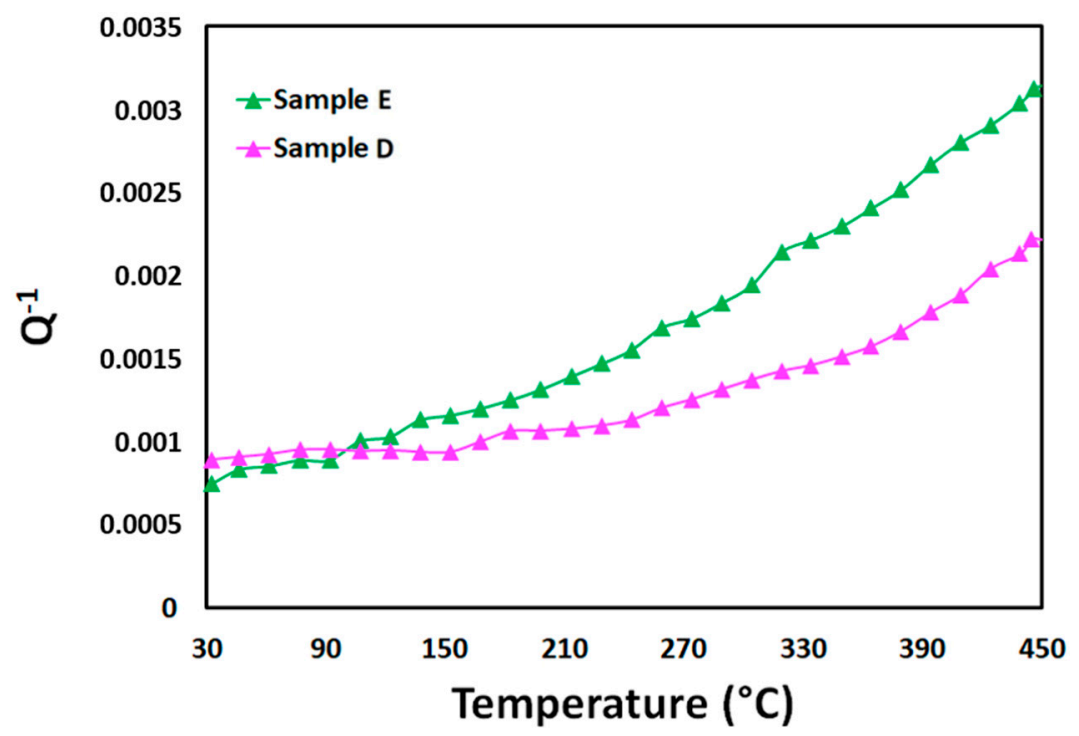

Figure 11. $Q^{-1}$ vs. temperature curves for hot dipped specimens with different aluminized coating thickness and successively annealed at $900{ }^{\circ} \mathrm{C}$ for $3 \mathrm{~h}$ and $4 \mathrm{~h}$, sample E and sample D, respectively.

A last group of specimens is made up of those annealed in an oxidative atmosphere: specimens $C$ and $\mathrm{F}$, which have the following configurations: specimen $\mathrm{C}$, starting from the steel interface: a fractured $\mathrm{Fe}_{2} \mathrm{Al}_{5}$ layer, followed by an $\mathrm{Al}-\mathrm{Si}$ alloy layer and an outer alumina layer, Figure $1 \mathrm{~b}$. Specimen $\mathrm{F}$ : a polycrystalline intermetallic structure made of $\mathrm{NiAl}, \mathrm{FeAl}$ plus an outer alumina layer. It must be pointed out that, as expected, intermetallic layers which have a comparable elastic modulus do not produce a relevant damping effect [8]. The result is a moderate increased damping compared with similar configurations characterized by a low difference in CTE between layers of Fe-Al and NiAl or alumina, Figure 1f. These intermetallic layers can exhibit high stress states, pores and cracks at the interfaces and do not exhibit viscoelastic behavior at room temperature. The multilayer coating of specimen F, has an internal friction comparable with that of specimen C, as reported in Figures 6 and 7 . This latter design should have in principle a significant damping while maintaining the same configuration of the as coated aluminized sample, with different relative thickness of the layers. Unfortunately, specimen $C$ has damping which is only slightly higher than that of the uncoated steel. The contribution to damping due to friction and slipping at the interface between layers seems to be 
negligible in this particular coating. This is reasonably due to delamination, which reduces adhesion between layers. Moreover, single polycrystalline intermetallic layers such as $\mathrm{FeAl}, \mathrm{Fe}_{2} \mathrm{Al}_{5}, \mathrm{NiAl}$ show small intrinsic damping due to the fine grain structure and the low viscoelasticity [31]. In fact, high Aluminum concentration in aluminides is detrimental to the mechanical property. Aluminum reaction with water produces Hydrogen atoms, which are in turn responsible for the low ductility of aluminides [30].

The low damping can be ascribed in both kinds of specimens to the weakly bonded interface between the bond coat NiAl layer and the steel substrate, Figure $1 \mathrm{f}$, and also to brittleness and cracks between the different CTE of steel and thick aluminide phase in specimen C. Finally, the grain boundary contribution to damping is, for structures with simultaneous formation of polycrystalline $\mathrm{FeAl}$ and $\mathrm{NiAl}$, rather poor because of intrinsic brittleness when these intermetallics are not produced in an inert atmosphere. Besides that, the polycrystalline structure is heavily tensioned, resulting in poor ductility of aluminides [30].

\section{Conclusions}

A first result of this study is the absence, below $200^{\circ} \mathrm{C}$, of a significant damping increase with respect to that of the substrate steel for all the tested multilayer coatings. Above that temperature, the structures which contain an Al-Si layer show damping exponentially increasing. Under these conditions, the predominant contribution to damping becomes viscoelastic, strongly influenced by the thickness of that layer.

The specimens with layers of $\mathrm{Fe}-\mathrm{Al}$ of variable thicknesses, show very tight interfaces. This multilayer configuration shows increased damping with respect to the reference steel, even if to a lesser extent when compared to the previous case. The main contribution to damping is now due to the sliding resistance of interfaces between layers and between the bond layer and the substrate.

No significant effects on damping are produced by intermetallic layers such as $\mathrm{NiAl}$, $\mathrm{FeAl}$ and Al-oxide. These ordered phases are stable up to temperatures greater than $550^{\circ} \mathrm{C}$. Moreover, they have inconsistent interfaces due to a different crystallographic structure, highly tensioned layers, intrinsic fragility and consequently poor adhesion between layers and substrate. This kind of multilayer configuration, also due to the intrinsic layer brittleness, does not present an appreciable dislocation contribution to damping as a function of temperature.

A final consideration is that in order to maximize the adhesion between interfaces, it is necessary that intermetallic layers be as thin as possible, particularly when they act as bond layers.

Author Contributions: Conceptualization, E.G.C. and A.C.; methodology, E.G.C., G.C., A.C. and, E.B.; validation, E.G.C., A.G.; E.B., and A.C.; data curation, A.G. and A.C.; writing-original draft preparation, E.G.C., G.C., and A.C.; writing-review and editing, E.G.C. and A.C.; supervision, E.G.C. and A.C. All authors have read and agreed to the published version of the manuscript.

Funding: This research received no external funding.

Acknowledgments: CIRI-MAM of Bologna University is gratefully acknowledged for its administrative and technical support.

Conflicts of Interest: The authors declare no conflict of interest.

\section{References}

1. Bouchaud, B.; Balmain, J.; Pedraza, F. Cyclic and Isothermal Oxidation at $1100{ }^{\circ} \mathrm{C}$ of a CVD Aluminised Directionally Solidified Ni Superalloy. Oxid. Met. 2008, 69, 193-210. [CrossRef]

2. Fu, G.; Wu, Y.; Liu, Q.; Li, R.; Su, Y. Hot Corrosion Behavior of Stainless Steel with Al-Si/Al-Si-Cr Coating. High Temp. Mater. Process. 2017, 36, 243-248. [CrossRef]

3. Boissonnet, G.; Chalk, C.; Nicholls, J.; Bonnet, G.; Pedraza, F. Phase stability and thermal insulation of YSZ and erbia-yttria co-doped zirconia EB-PVD thermal barrier coating systems. Surf. Coat. Technol. 2020, 389, 125566. [CrossRef] 
4. Meetham, G.W.; Van De Voorde, M.H. Materials for High Temperature Engineering Applications; Springer Science and Business Media LLC: Berlin, Germany, 2000.

5. Young, D.J. High Temperature Oxidation and Corrosion of Metals; Elsevier Corrosion Series; Elsevier: Amsterdam, The Netherland, 2008; Volume 1, ISBN 978-0-08-044587-8.

6. Chung, D.D.L. Review: Materials for vibration damping. J. Mater. Sci. 2001, 36, 5733-5737. [CrossRef]

7. Ritchie, I.G.; Pan, Z.-L. High-damping metals and alloys. Trans. A Met. Mater. Sci. 1991, 22, 607. [CrossRef]

8. Casadei, F.; Bertoldi, K.; Clarke, D.R. Vibration Damping of Thermal Barrier Coatings Containing Ductile Metallic Layers. J. Appl. Mech. 2014, 81, 101001. [CrossRef]

9. Kerwin, E.M., Jr.; Ungar, E.E. Proceedings of the ACS Division of Polymeric Materials: Science and Engineering, Dallas, Spring 1989; ACS: Washington, DC, USA, 1989; Volume 60, p. 816.

10. De Batist, R. High Damping Materials: Mechanisms and Applications. J. Phys. Colloq. 1983, 44, C9-39-C9-50. [CrossRef]

11. Griffin, J.H. A Review of Friction Damping of Turbine Blade Vibration. Int. J. Turbo Jet-Engines 1990, 7, $297-308$. [CrossRef]

12. Cammarota, G.; Casagrande, A.; Sambogna, G. Effect of Ni, Si and Cr in the structural formation of diffusion aluminide coatings on commercial-purity titanium. Surf. Coat. Technol. 2006, 201, 230-242. [CrossRef]

13. Yu, L.; Ma, Y.; Zhou, C.; Xu, H. Damping efficiency of the coating structure. Int. J. Solids Struct. 2005, 42, 3045-3058. [CrossRef]

14. Matysik, P.; Jóźwiak, S.; Czujko, T. Characterization of Low-Symmetry Structures from Phase Equilibrium of Fe-Al System-Microstructures and Mechanical Properties. Materials 2015, 8, 914-931. [CrossRef] [PubMed]

15. Hu, J.; Liu, G.; Tang, S. Damping behavior in Al18B4O33w/Al composite containing an interfacial layer with low melting point metal particles. J. Alloy. Compd. 2012, 513, 61-67. [CrossRef]

16. Zhang, Y.; Pint, B.A.; Garner, G.; Cooley, K.; Haynes, J. Effect of cycle length on the oxidation performance of iron aluminide coatings. Surf. Coat. Technol. 2004, 188, 35-40. [CrossRef]

17. Bonetti, E.; Campari, E.G.; Pasquini, L.; Savini, L. Automated resonant mechanical analyzer. Rev. Sci. Instruments 2001, 72, 2148-2152. [CrossRef]

18. Amadori, S.; Campari, E.; Fiorini, A.; Montanari, R.; Pasquini, L.; Savini, L.; Bonetti, E. Automated resonant vibrating-reed analyzer apparatus for a non-destructive characterization of materials for industrial applications. Mater. Sci. Eng. A 2006, 442, 543-546. [CrossRef]

19. Blanter, M.S.; Golovin, I.S.; Neuhäuser, H.; Sinning, H.-R. Internal Friction in Metallic Materials; Springer Series in Materials Science; Springer: Berlin/Heidelberg, Germany, 2007.

20. Richards, R.W.; Jones, R.D.; Clements, P.D.; Clarke, H. Metallurgy of continuous hot dip aluminizing. Int. Mater. Rev. 1994, 39, 191. [CrossRef]

21. Kobayashi, S.; Yako, T. Control of intermetallic compound layers at interface between steel and aluminum by diffusion-treatment. Mater. Sci. Eng. A 2002, 338, 44-53. [CrossRef]

22. Kepa, T.; Pedraza, F.; Rouillard, F. Intermetallic formation of Al-Fe and Al-Ni phases by ultrafast slurry aluminization (flash aluminizing). Surf. Coat. Technol. 2020, 397, 126011. [CrossRef]

23. Akuezue, H.C.; Whittle, D.P. Interdiffusion in Fe-Al system: Aluminizing. Met. Sci. 1983, 17, $27-31$. [CrossRef]

24. Tortorici, P.C.; Dayananda, M.A. Phase formation and interdiffusion in Al-clad 430 stainless steel. Mater. Sci. Eng. A 1998, 244, 207-215. [CrossRef]

25. Švec, M.; Hanus, P.; Vodičková, V. Coefficient Thermal Expansion of $\mathrm{Fe}_{3} \mathrm{Al}$ and FeAl-type iron aluminides. Manuf. Technol. 2013, 13, 399-404. [CrossRef]

26. Babu, N.; Balasubramaniam, R.; Ghosh, A. High-temperature oxidation of $\mathrm{Fe}_{3} \mathrm{Al}$-based iron aluminides in oxygen. Corros. Sci. 2001, 43, 2239-2254. [CrossRef]

27. ASM. ASM Handbook, Alloys Phase Diagrams; ASM International Materials Park: Novelty, OH, USA, 1992; Volume 3.

28. Berry, B.S. Anelastic Relaxation and Diffusion in Thin-Layer Materials. In Diffusion Phenomena in Thin Films and Microelectronic Materials; Gupta, D., Ho, P.S., Eds.; Noyes Press: Park Ridge, NJ, USA, 1988; pp. $73-145$.

29. Zamanzade, M.; Barnoush, A.; Motz, C. A Review on the Properties of Iron Aluminide Intermetallics. Crystals 2016, 6, 10. [CrossRef] 
30. Zamanzade, M.; Barnoush, A. An Overview of the Hydrogen Embrittlement of Iron Aluminides. Procedia Mater. Sci. 2014, 3, 2016-2023. [CrossRef]

31. Khor, K.A.; Chia, C.T.; Gu, Y.W.; Boey, F.Y.C. High Temperature Damping Behavior of Plasma Sprayed NiCoCrAlY Coatings. J. Therm. Spray Technol. 2002, 11, 359-364. [CrossRef]

(C) 2020 by the authors. Licensee MDPI, Basel, Switzerland. This article is an open access article distributed under the terms and conditions of the Creative Commons Attribution (CC BY) license (http://creativecommons.org/licenses/by/4.0/). 